\title{
The facilitating effect of conflict measured with the probe stimulus technique
}

\author{
DONALD R. YELEN \\ Washburn University, Topeka, Kansas 66621
}

\begin{abstract}
The present experiment used the Brown, Kalish, and Farber (1951) probe stimulus technique to determine the facilitating effect of conflicts produced with the Yelen $(1969,1979)$ procedure. The results from 54 college students indicated that when a probe stimulus was presented during a conflict trial, the latency of GSR was significantly faster than when the probe was presented during a nonconflict trial. The results, then, provide another source of evidence for the energizing property of conflict.
\end{abstract}

Conflicts defined by the simultaneous arousal of incompatible responses are assumed to have drive properties and, thus, are expected to facilitate or energize responses when they occur (Brown \& Farber, 1951; Miller, 1959). Evidence for the energizing property of conflict, however, is limited to a few studies: Castaneda and Worell (1961) and Yelen $(1969,1979)$. The purpose of the present experiment was to provide another source of evidence for the facilitating or energizing property of conflict.

\section{METHOD}

The present experiment used the probe stimulus technique developed by Brown, Kalish, and Farber (1951) to measure the energizing property of conflicts that were produced with Yelen's $(1969,1979)$ method. With Yelen's method, a conflict requires the presentation of three stimuli in the following sequence. First, two stimuli, each designating a different response to be made, are simultaneously presented, and then, after an interval of time, a signal to respond is given and the subject is free to make either one of the two responses.

Brown et al. (1951) devised the probe stimulus technique as an indirect measure of fear and its energizing property. The rationale underlying the technique is that the energizing property of fear, or of any source of drive for that matter, can be measured through its effects on the strength of an overt reference response. The technique requires a stimulus, the probe stimulus, which reliably elicits an overt response. The probe stimulus is presented under two conditions: first, when a source of drive is assumed to be strong, or at least present, and second, when drive is assumed to be weak or absent. The strength of the reference response is expected to be enhanced or energized when it is elicited in the condition in which a source of drive is assumed to be strong or at least present.

In the present experiment, a conflict was produced by simultaneously presenting two stimuli, each designating a different response to be made. While these stimuli were present, but before the signal to respond was given, a probe stimulus was presented. The latency of the reference response to the probe stimulus under these conditions was compared with the latency of the same response under nonconflict conditions, that is, conditions in which only one of the competing responses was to be made. The difference in the latency of the reference response under these two conditions was used as the measure of the facilitating or energizing property of conflict.

\section{Apparatus}

A stimulus display panel, a response keyboard, and conventional controlling and measuring devices were used to produce a conflict. The stimulus display panel with three lights mounted on it, one green light in the center and a yellow light in both the top left-hand and the top right-hand corners, was placed in front of a typing table. The response keyboard with a starting block and two response levers, one $10 \mathrm{~cm}$ to the left and one $10 \mathrm{~cm}$ to the right of the starting block, was attached to the writing surface of the typing table. Silent Hunter timers were used to control the onset and offset of the lights. Gerbrands digital clocks were used to measure the latencies of the leverpressing responses.

The probe stimulus technique used the following apparatus: a doorbell buzzer, two finger electrodes, a two-channel Stoelting polygraph, and silent timing devices. The doorbell buzzer, which produced a sound judged to be loud and noxious, served as the probe stimulus. The onset and duration of the buzzer were controlled with Hunter timers. The galvanic skin response (GSR) elicited by the sound of the buzzer was used as the reference response. One channel on the polygraph was used to mark the onset of the buzzer, and the second channel was used to record the GSR. The latency of the GSR to the sound of the buzzer was measured with a template placed over the recordings made on test trials.

\section{Procedure}

Students were told that the experiment was concerned with the effects of noise on a physiological response and on the speed of a response to lights. Instructions for the task were given to the students while recording electrodes for the GSR were attached to the first and third fingers of their left hands. The instructions indicated that the students were to get ready to respond by placing the index finger of the right hand on the starting block when either one or both of the top lights came on. The students were then to wait until the center lights came on, and at that time they were to press one of the response levers as quickly as possible. The left lever was to be pressed if only the left light had been presented, and the right lever was to be pressed if only the right light had been presented. The students were instructed that they were free to press either one of the levers if both of the top lights had been presented.

A total of 71 trials on the task were then administered to each student. Trials 1-61 were training trials. Each of these trials involved the onset of either the left or the right top light and then, after a 4-sec interval, the onset of the center light. Half of these trials required a response to the left, and half required a response to the right. 
Trials 61-71 included one conflict test trial, two nonconflict test trials, and eight filler trials. During the conflict test trial, the two top lights were simultaneously presented, and then, after a 3-sec interval, the buzzer, or probe stimulus, was sounded for $.5 \mathrm{sec}$. The conflict trial ended with the onset of the center light $4 \mathrm{sec}$ after the initial presentation of the two top lights. The nonconflict test trials involved the onset of either the left or the right top light, and then, after a 3-sec interval, the buzzer, or probe stimulus, was sounded for $.5 \mathrm{sec}$. Each nonconflict trial ended with the presentation of the center light $4 \mathrm{sec}$ after the onset of one of the top lights. One of the nonconflict test trials required a response to the left, and the other required a response to the right. The filler trials were the same as training trials and were used to insure that there would be a 1-min interval between the three test trials.

\section{Subjects}

A total of 54 introductory psychology students participated in this experiment. Each student received the same treatment, except that the order and sequence of the conflict and nonconflict test trials were counterbalanced in order to control for the possible adaptation of the GSR to the sound of the buzzer.

\section{RESULTS}

The mean latency of the GSR to the sound of the buzzer was $1.43 \mathrm{sec}$ during the conflict test trial. The mean latencies for the GSRs during the two nonconflict tests were $2.83 \mathrm{sec}$ for the trial requiring a response to the left and $2.67 \mathrm{sec}$ for the trial requiring a response to the right. A series of $t$ tests indicated that the mean GSR latency during the conflict test trial was significantly shorter than the mean GSR latency during the nonconflict test trial requiring a response to the left $[\mathrm{t}(53)=7.38, \mathrm{p}<.001]$ and during the nonconflict test trial requiring a response to the right $[\mathrm{t}(53)=6.66$, $p<.001]$. The difference between the mean latencies of the GSRs during the two nonconflict test trials was not significant $[\mathrm{t}(53)=.78, \mathrm{p}>.10]$.

The results of the present experiment indicate, then, that the latency of the reference response was faster under conflict conditions than under nonconflict conditions, and they thus provide evidence for the facilitating or energizing effect of conflict.

\section{DISCUSSION}

A previous study (Yelen, 1979) has indicated that interference is likely to be observed when the response measure is taken before there is an opportunity to resolve the conflict. Response measures taken at this time are expected to reflect the resolution process. To the extent that the resolution process involves competition between the response alternatives, we should observe vacillation, hesitation, and even blocking. In the present experiment, the reference response was measured before the conflict could be resolved, but a facilitating or energizing effect was observed. The difference between the previous study and the present experiment can be reconciled by noting that the response measured in the present experiment was independent of the conflict and, therefore, was not involved in the resolution process. Since the response in the present experiment was independent of the conflict but was elicited during the conflict, the performance of the response was enhanced or facilitated by the presence of conflict-produced drive.

\section{REFERENCES}

Brown, J. S., \& Farber, I. E. Emotions conceptualized as intervening variables-With suggestions toward a theory of frustration. Psychological Bulletin, 1951, 48, 465-495.

Brown, J. S., Kalish, H. I., \& Farber, I. E. Conditioned fear as revealed by magnitude of startle response to an auditory stimulus. Journal of Experimental Psychology, 1951, 41, 317-328.

Castaneda, A., \& Worell, L. Differential relation of latency and response vigor to stimulus similarity in brightness discrimination. Journal of Experimental Psychology, 1961, 61, 309-314.

Miller, N. E. Liberalization of basic S-R concepts: Extensions to conflict behavior, motivation, and social learning. In S. Koch (Ed.), Psychology: A study of a science (Vol. 2). New York: McGraw-Hill, 1959.

YelEN, D. R. The effects of strength of competing responses during conflict. Psychonomic Science, 1969, 15, 80-81.

YELEN, D. R. Paradoxical consequences of conflict: Interference and facilitation. Bulletin of the Psychonomic Society, 1979, 14, 121-123.

(Received for publication April 15, 1980.) 